\title{
Comparison of American Binomial Options with Discrete and Continuous Dividend
}

\author{
Dian Ayu Merdekawati, Yolanda Norasia, Charisma Juni Kumalasari and Endah Rokhmati Merdika Putri
}

\begin{abstract}
This study discusses the effect of dividend on option pricing by using a binomial method. It also investigated the initial stock value, number of steps, and strike price effects on the behavior of options pricing. From several simulations conducted, it was found that the values of call options with discrete dividend are greater than the continuous dividend. While on the put option, the values of the put options with a continuous dividend are greater than the discrete dividend.
\end{abstract}

Index Terms-Option pricing, American option, binomial method, dividend.

\section{INTRODUCTION}

A $\mathrm{N}$ option is a legal contract between a buyer and seller that gives a right to buy or sell an asset at a specified price and time period. The options are divided into two types namely the call option and put option. Based on the exercise time, options can be differentiated into several types those are European options and American options. The difference between European options and American options is about the time of exercise. European options can be exercised just at maturity time. Then American options can be exercised any time before maturity time. Besides depending on the movement of the underlying assets, the value of the option contract is also influenced by a dividend distribution or profit sharing that is obtained by the company once a year for each shareholder. Dividends are divided into two, there are discrete and continuous dividends.

A binomial tree is a method that uses discrete lattice and an iterative procedure which can be applied in an option price. This method is allowing for the specification of nodes, or point in time, during the time span between initial date and the option's maturity date. The tree of the binomial method starts with the spot price today and depends on the outcome of the probability when a stock price is "up" with the probability $p$ and when a stock price is "down" with the probability $q$ in the next time step. The existing study of a binomial option pricing model is by Cox, Ross, and Rubinstein in 1979 [1].

The previous research about the exercise on a determination of American option pricing conducted by Schumann et al [2] and Barone et al [3] determine stock option value using discrete with a binomial tree method. Bin Peng and Fei Peng [4] was performed the binomial method and the combined option method. Research with discrete dividends was performed by Guochao Jiang et al [5], that shows the discount process of the stock price is a martingale.

Manuscript received August 23, 2018; accepted August 17, 2020.

The authors are with the Department of Mathematics, Institut Teknologi Sepuluh Nopember, Kampus ITS Sukolilo-Surabaya 60111, Indonesia. E-mail: endahrmp@matematika.its.ac.id
This study aims to observe the difference of the result American option pricing with discrete and continuous dividend to see the advantages and disadvantages of the dividend. This paper is organized as follows. Section I describes the introduction. Section II discusses the binomial tree method. Section III explains dividend, and the last section discusses about the simulation.

\section{Binomial Tree Method}

The tree has $N$ time steps corresponding to times $k=$ $0,1, \ldots, N$ and models an asset price $S_{k}$. The price is normalized to $S_{0}=1$, at each branch in the tree the price moves up to $S_{k+1}=u S_{k}$ or down to $S_{k+1}=d S_{k}$ where $u>1$ and $d=\frac{1}{u}$ so that the tree is re-combining; see Figure 1.1. By defining the 'up' probability $p$ (the same at every node). Let $F$ be the $\sigma$ field generated by $\left\{S_{0}, S_{1}, \ldots, S_{k}\right\}$ at time $k$ the possible price values are specified by a vector $s_{k}=s_{k}[0], \ldots, s_{k}[k]$ where

$$
s_{k}[j]=u^{k} d^{2 j}=d^{2 j-k}
$$

so that $s_{k}[0]=u_{k}, s_{k}[k]=d_{k}$, i.e. the prices are listed in decreasing order if invested. There is a riskless savings account such that $\$ 1$ invested at time $k$ is worth $\$ R$ at time $k+1$. The condition for no arbitrage is using the finite difference method, as follows

$$
d<R<u
$$

The probability $p$ is risk neutral if the discounted price $S_{k} / R^{k}$ is a martingale. At time $t=0$ this requires

$$
S_{0}=1=\frac{1}{R}(p u+(1-p) d)=E\left[\frac{S_{1}}{R}\right]
$$

and we note that $0<p<1$ if and only if (2) holds.

Most of the time, identifying the node the price process is at $k$ rather than the actual value $S_{k}$ of the price. If it is defined

$$
J_{k}=\frac{1}{2} k+\left(\frac{\log S_{k}}{\log d}\right)
$$

then from (1), we see that if $S_{k}=d^{2 j-k}$ then $J_{k}=j$, so $J_{k}=j$ is the process followed by the index of the price. Since there is (at each $k$ ) a 1-1 correspondence between $S_{k}$ and $J_{k}$, the $\sigma$-field these processes generate are the same: $F_{k}=\sigma\left\{S_{0}, S_{1}, \ldots, S_{k}\right\}=$ $\sigma\left\{J_{0}, J_{1}, \ldots, J_{k}\right\}$.

\section{A. Binomial Tree Method for European Call Option}

The exercising of European options use binomial tree method can be applied just at the maturity time. The payoff value at maturity for a European option call is calculated using the formula:

$$
f_{0}=\left(p f_{u}+(1-p) f_{d}\right) e^{r \Delta t}
$$




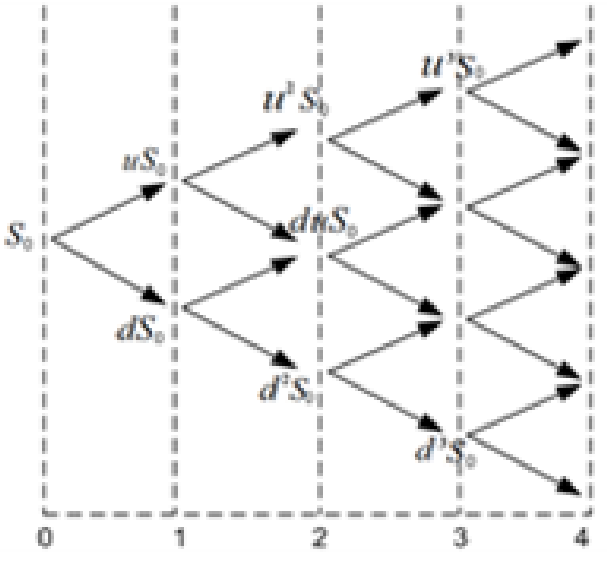

Fig. 1: Binomial tree with $N=4$ steps.

Probability $q$ of the stock "down" is given as follows

$$
q=1-p
$$

\section{B. Binomial Tree Method for American Call Option}

American option exercising with binomial tree method can be used to calculate the options value at each node over the life time of the options. The pay-off value of an American call options at maturity is calculated using the following formula. The formula for $f_{u_{(a m)}}$ is given as follow

$$
f_{u_{(a m)}}=\max \left(f_{u}, v_{u}\right)
$$

whereas the formula for $f_{d_{(a m)}}$ is

$$
f_{d_{(a m)}}=\max \left(f_{d}, v_{d}\right)
$$

with same formula for $p$ and $q$. The American call option is given as

$$
f_{0}=\left(p f_{u_{(a m)}}+(1-p) f_{d_{(a m)}}\right) e^{r \Delta t}
$$

\section{DIVIDENDS}

Dividends can be classified into two types: First, Dividend is paid as a percentage of the stock price and second, dividend is paid as a fixed amount of money. Furthermore, we restrict that the dividend be paid once during the time of maturity, i.e. $t^{*}$, $0<t^{*} \leq T$. Based on arbitrage theory, the stock price decreases of the dividend amounts when the dividend is paid. The time $t^{*}-d t$ occurs before dividends are paid. Furthermore, The stocks are bought by getting dividend and sell stock at time $t^{*}+d t$. As a result, we gain the following benefits:

$$
D+S_{t}^{*}+d t-S_{t}^{*}-d t
$$

It will be zero if there is no arbitrage. therefore, for $d t \rightarrow 0$, $S_{t}$ will decrease by $D$ at time $t^{*}$. Assumed that at time $t^{*}$, a fixed amount of money has been paid. Thus, the value of the stocks with fall. This causes the tree can not be merged again. A tree of stock price ends with the following example: at time $t^{*}$, a fixed dividend $D$ have been paid, with $t_{1}<t^{*} \leq t_{2}<T$ before dividend is paid on $t=1$, the stock price is $u S_{0}$ and $S_{0} / u$ and at time $t_{2}$, given $u^{2} S_{0}-D, S_{0}-D$, and $\frac{S_{0}}{u^{2}}-D$.
TABLE I: Comparison Between American Option With Discrete and Continuous Dividend With $\mathrm{K}=34, \mathrm{~N}=12$ and Different Initial Stock Value

\begin{tabular}{c||cc||cc}
\hline \multicolumn{1}{c||}{ Stock } & \multicolumn{2}{c||}{ Call Option } & \multicolumn{2}{c}{ Put Option } \\
& Discrete & Continuous & Discrete & Continuous \\
\hline \hline 50 & 17.908 & 16.6788 & 1.6051 & 1.9497 \\
120 & 77.5232 & 86.5491 & 0.00082888 & 0.0018000 \\
160 & 97.5232 & 126.4453 & 0 & 0 \\
190 & 217.5232 & 156.4453 & 0 & 0 \\
250 & 917.5232 & 216.4453 & 0 & 0 \\
500 & 1217.500 & 466.4453 & 0 & 0 \\
700 & 1667.500 & 666.4453 & 0 & 0 \\
1250 & 1967.500 & 1216.4000 & 0 & 0 \\
1700 & 2667.500 & 1666.400 & 0 & 0 \\
2500 & 2967.500 & 2466.400 & 0 & 0 \\
3000 & 3026.300 & 2964.400 & 0 & 0 \\
\hline
\end{tabular}

\section{Mathematical Simulations}

On this research, we do some simulations to know how discrete and continuous dividends affect the option price. Consider an American call option on a stock. A stock price is currently $\$ 50$. Over each of the next two 6-month periods, it is expected to go up by $\$ 5.2$ or down by $\$ 4$ with dividends yield. The risk-free interest rate is $\$ 5$ per annum with continuous compounding, and the volatility is 0.3 . In this simulation, we calculate the value of 1-year American call options with a strike price of $\$ 34$. From this information, we have $S_{0}=50$, $u=5.2 \%, d=4 \%, r=5 \%, \sigma=0.3$ and $K=38$.

This simulation shows the difference of value option when probability is up and down. On the first simulation, given some different initial stock price, strike price value is 34 dollars, and number of steps is 12 . Results from different value will be presented in the following subsection.

\section{A. Comparison of discrete and continuous dividends with different initial stock price}

Comparison results for option value for discrete and continuous dividend with different initial stock price will be discussed in this section. Particularly, this section will see how strike price and number of step will affect the options value.

Let be given strike price and number of step with small value that is $K=38$ and $N=12$. The results of the simulation are shown in Table I:

Table I shows that the option value increases both for discrete and continuous dividend with respect to the initial stock price. Specifically, the result for call option price with discrete dividend has a higher value than continuous dividend. On the other hand, the result for put option shows differently. The put option price for continuous dividend is greater than put option price for discrete dividend.

On the next simulation, by comparing result with greater $N=1100$, we obtain results that are shown on Table II. The option values of both call and put options are smaller than the option price result with $N=34$. It can be seen that the greater $N$ value gives an accurate result than when $N$ value is small. The call options results with discrete dividend are higher than 
TABLE II: Comparison with $K=34, N=1100$ and Different Initial Stock Value

\begin{tabular}{c||cc||cc}
\hline \multirow{2}{*}{ Stock } & \multicolumn{2}{c||}{ Call Option } & \multicolumn{2}{c}{ Put Option } \\
& Discrete & Continuous & Discrete & Continuous \\
\hline \hline 50 & 16.6780 & 16.0049 & 1.3079 & 1.7799 \\
120 & 86.0170 & 86.0049 & 0.0027 & 0.0055 \\
160 & 126.0170 & 126.0049 & $1.4027 \times 10^{-4}$ & $3.2918 \times 10^{-4}$ \\
190 & 156.0170 & 156.0049 & $1.913 \times 10^{-5}$ & $4.882 \times 10^{-5}$ \\
250 & 216.0170 & 216.0049 & $5.4350 \times 10^{-7}$ & $1.5872 \times 10^{-6}$ \\
500 & 466.0170 & 466.0049 & $9.068 \times 10^{-12}$ & $3.7207 \times 10^{-11}$ \\
700 & 666.0170 & 666.0049 & $1.4856 \times 10^{-14}$ & $7.1939 \times 10^{-14}$ \\
1250 & $1.216 \times 10^{3}$ & $1.216 \times 10^{3}$ & $4.3316 \times 10^{-20}$ & $2.7925 \times 10^{-19}$ \\
1700 & $1.666 \times 10^{3}$ & $1.666 \times 10^{3}$ & $1.9967 \times 10^{-23}$ & $1.4999 \times 10^{-22}$ \\
2500 & $2.466 \times 10^{3}$ & $2.466 \times 10^{3}$ & $5.4807 \times 10^{-28}$ & $4.9858 \times 10^{-27}$ \\
3000 & $2.966 \times 10^{3}$ & $2.966 \times 10^{3}$ & $2.7950 \times 10^{-30}$ & $2.7778 \times 10^{-29}$ \\
\hline
\end{tabular}

TABLE III: Comparison With $S=50, K=34$ and Different Strike Price Value

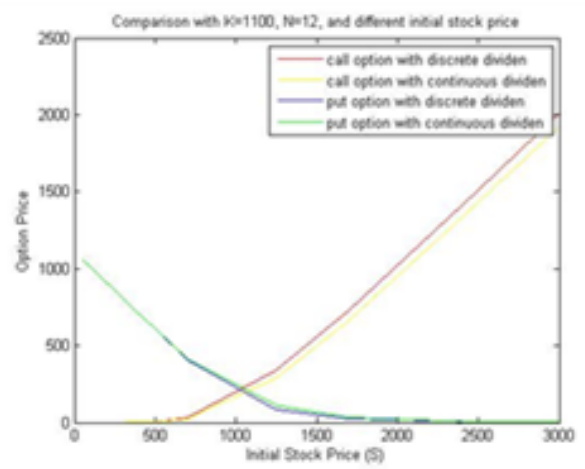

Fig. 2: Comparison graphic with $K=1100, N=12$, and different initial stock value.

the continuous dividend results, and the put options results with continuous dividend are higher than the discrete dividend results.

Given a greater strike price value than previous simulations. The results for $K=1100$ and $N=12$ are shown on Fig. 2 .

In contrast to the results when the value of $K$ is small, this simulation shows that the large $K$ giving an effect on the put option decreasing. It can be seen that the prices of put options are decreased as the initial stock prices are increased. The call options are increased as the initial stock prices are increased. The call options result with discrete dividends are higher than the results with continuous dividend, and the put option results with continuous dividends are higher than the discrete dividend.

Figure 3 shows the comparison results for $K=1000$ and $N=1100$. It can be seen that the greater $N$ value gives more accurate result than $N$ value is small. The prices of put options are decreased as the initial stock prices are increased. The call options are increased as the initial stock prices are increased. The call options results with discrete dividends are higher than the results with continuous dividends, and the put option results with continuous dividends are higher than the result with discrete dividends.

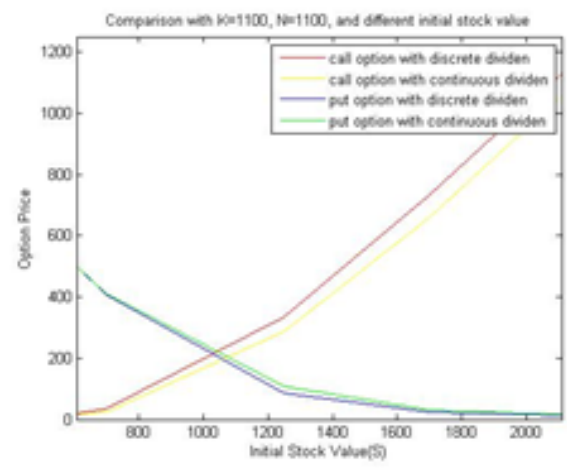

Fig. 3: Comparison graphic with $K=1100, N=1100$, and different initial stock value.

\begin{tabular}{c||cc||cc}
\hline \multicolumn{1}{c||}{$\mathbf{N}$} & \multicolumn{2}{c||}{ Call Option } & \multicolumn{2}{c}{ Put Option } \\
& Discrete & Continuous & Discrete & Continuous \\
\hline \hline 10 & 18.2157 & 16.8086 & 1.4344 & 1.9469 \\
35 & 16.9484 & 16.2247 & 1.3005 & 1.7876 \\
70 & 16.7467 & 16.0951 & 1.2927 & 1.7727 \\
150 & 16.6958 & 16.0300 & 1.2989 & 1.7738 \\
180 & 16.6840 & 16.0300 & 1.2989 & 1.7738 \\
220 & 16.6876 & 16.0246 & 1.3057 & 1.7814 \\
300 & 16.6845 & 16.0180 & 1.3062 & 1.7814 \\
500 & 16.6809 & 16.0108 & 1.3068 & 1.7805 \\
1100 & 16.6780 & 16.0049 & 1.3079 & 1.7799 \\
2400 & 16.6766 & 16.0023 & 1.3087 & 1.7796 \\
3000 & 16.6764 & 16.0018 & 1.3089 & 1.7795 \\
\hline
\end{tabular}

B. Comparison of discrete and continuous dividends with different number of steps

In this section, we do some simulations with different number of steps. Table III has shown the comparison results for $S=50, K=34$, and a given $N$. The greater $N$ values, the more accurate option value. But it does not gives significant effect to the movements of option pricing. The call options results with discrete dividends are higher than the results with continuous dividends, Then the put options result with continuous dividends are higher than the results with discrete dividends.

Given a greater strike price value than previous simulations. The results for $S=50$ and $K=1100$ are shown on Table IV. Same as before, the given $N$ with $S=50$ and $K=1100$ does not give significant effect to the movements of option pricing. The result shows that the options price with $K=1100$ are smaller than the previous option price when $K=34$. The call option result with discrete dividends are higher than the results with continuous dividends. Then the put options result with continuous dividends are higher than the result with discrete dividends.

We do simulation for $S=1000$ and $K=34$. The result that have been shown on Table $\mathrm{V}$ describes the greater $N$ gives more accurate increasing of option value. Same as before, it does not gives significant effect to the movements of option 
TABLE IV: Comparison With $S=50, K=34$ and Different Strike Price Value

\begin{tabular}{c||cc||cc}
\hline \multicolumn{1}{c||}{$\mathbf{N}$} & \multicolumn{2}{c||}{ Call Option } & \multicolumn{2}{c}{ Put Option } \\
& Discrete & Continuous & Discrete & Continuous \\
\hline \hline 10 & 0 & 0 & $1.0577 \times 10^{3}$ & $1.0577 \times 10^{3}$ \\
35 & 0 & 0 & $1.0579 \times 10^{3}$ & $1.0579 \times 10^{3}$ \\
70 & $8.8386 \times 10^{-18}$ & $1.8811 \times 10^{-18}$ & $1.0580 \times 10^{3}$ & $1.0580 \times 10^{3}$ \\
150 & $6.6296 \times 10^{-15}$ & $1.4147 \times 10^{-15}$ & $1.0580 \times 10^{3}$ & $1.0580 \times 10^{3}$ \\
180 & $1.0246 \times 10^{-14}$ & $2.1723 \times 10^{-15}$ & $1.0580 \times 10^{3}$ & $1.0580 \times 10^{3}$ \\
220 & $1.6421 \times 10^{-14}$ & $3.4843 \times 10^{-15}$ & $1.0580 \times 10^{3}$ & $1.0580 \times 10^{3}$ \\
300 & $2.8417 \times 10^{-14}$ & $6.0262 \times 10^{-15}$ & $1.0580 \times 10^{3}$ & $1.0580 \times 10^{3}$ \\
500 & $4.7394 \times 10^{-14}$ & $1.0028 \times 10^{-14}$ & $1.0581 \times 10^{3}$ & $1.0581 \times 10^{3}$ \\
1100 & $7.0547 \times 10^{-14}$ & $1.4906 \times 10^{-14}$ & $1.0581 \times 10^{3}$ & $1.0581 \times 10^{3}$ \\
2400 & $8.3529 \times 10^{-14}$ & $1.7636 \times 10^{-14}$ & $1.0581 \times 10^{3}$ & $1.0581 \times 10^{3}$ \\
3000 & $8.5877 \times 10^{-14}$ & $1.8129 \times 10^{-14}$ & $1.0581 \times 10^{3}$ & $1.0581 \times 10^{3}$ \\
\hline
\end{tabular}

TABLE V: Comparison With $S=50, K=34$ and Different Strike Price Value

\begin{tabular}{c||cc||cc}
\hline \multirow{2}{*}{ Stock } & \multicolumn{2}{c||}{ Call Option } & \multicolumn{2}{c}{ Put Option } \\
& Discrete & Continuous & Discrete & Continuous \\
\hline \hline 12 & 967.5232 & 966.4453 & 0 & 0 \\
35 & 966.5301 & 966.1538 & 0 & 0 \\
70 & 966.2661 & 966.0771 & 0 & 0 \\
250 & 966.1244 & 966.0360 & $3.2829 \times 10^{-19}$ & $1.9207 \times 10^{-18}$ \\
280 & 966.1037 & 966.0300 & $6.7630 \times 10^{-19}$ & $3.9541 \times 10^{-18}$ \\
330 & 966.0849 & 966.0246 & $1.2283 \mathrm{TT}$ & $7.1701 \times 10^{-18}$ \\
400 & 966.0623 & 966.0180 & $2.1388 \times 10^{-18}$ & $1.2522 \times 10^{-17}$ \\
500 & 966.0374 & 966.0108 & $4.5728 \times 10^{-18}$ & $2.6547 \times 10^{-17}$ \\
1100 & 966.0170 & 966.0049 & $7.4007 \times 10^{-18}$ & $4.2727 \times 10^{-17}$ \\
2400 & 966.0078 & 966.0023 & $9.4845 \times 10^{-18}$ & $5.4503 \times 10^{-17}$ \\
3000 & 966.0062 & 966.0018 & $9.8502 \times 10^{-18}$ & $5.6576 \times 10^{-17}$ \\
\hline
\end{tabular}

pricing. On this simulation, the call option with discrete dividends are higher than the results with continuous dividends. Then the put options result with continuous dividends are higher than the result with discrete dividends.

Given a greater number of initial stock value and strike price, the results for $S=1000$ and $K=1100$ are shown on Fig. 4. Same as before, the given $N$ does not give significant effect to the movements of option pricing, but it can be seen that each line on Fig. 4 going convergent to a certain value. Furthermore, the options price with $K=1100$ gives a higher put option value than when $K=34$, but the call options value is smaller than previous simulation. The call option result with discrete dividends are higher than the results with continuous dividends. Then the put options result with continuous dividends are higher than the result with discrete dividends.

\section{Comparison of discrete and continuous dividends with different strike price}

In this section, we do some simulations with different strike values. Specifically, on this simulation, let be given small value of initial stock price that is $S=50$ and small number of step that is $N=12$. Table VI shows there is no significant movement of the call options value, since the result is 0 for

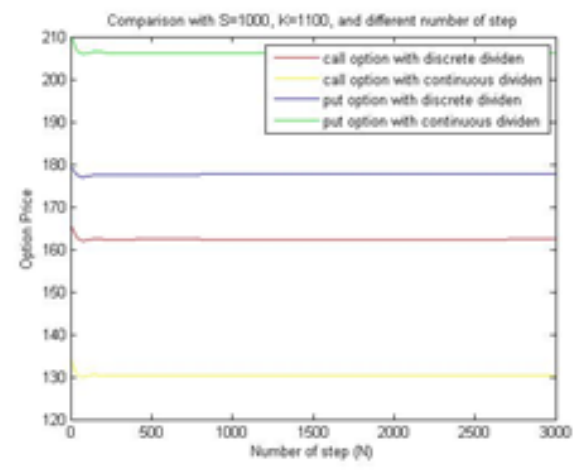

Fig. 4: Comparison graphics with $S=1000, K=1100$, and different initial stock value.

TABLE VI: Comparison With $S=50, N=12$ and Different Strike Price Value

\begin{tabular}{c||cc||cc}
\hline \multicolumn{1}{c||}{ K } & \multicolumn{2}{c||}{ Call Option } & \multicolumn{2}{c}{ Put Option } \\
& Discrete & Continuous & Discrete & Continuous \\
\hline \hline 34 & 17.9083 & 16.6788 & 1.6051 & 1.94973 \\
80 & 1.5390 & 1.0806 & 37.7003 & 37.7003 \\
105 & 0.3503 & 0.2247 & 62.7003 & 62.7003 \\
200 & 0 & 0 & 157.7003 & 157.7003 \\
350 & 0 & 0 & 307.7003 & 307.7003 \\
500 & 0 & 0 & 457.7003 & 457.7003 \\
900 & 0 & 0 & 857.700 & 857.7003 \\
1100 & 0 & 0 & 1057.700 & 1057.700 \\
1800 & 0 & 0 & 17577.700 & 1757.700 \\
2500 & 0 & 0 & 2457.700 & 2457.700 \\
3000 & 0 & 0 & 2957.700 & 2957.700 \\
\hline
\end{tabular}

$K=200$ so on. But differently with the put options, there is an increasing movement of put options value with respect to the increasing of strike price. The put options with continuous dividends has higher value than put option value with discrete dividends. Then the call options results with discrete dividends are higher than the results with continuous dividends.

Table VII shows the result for $S=50$ and $N=1100$. Comparing with the previous simulation result with small $N$, the great $N$ gives more accurate result for option values. There is a decreasing of call option value with respect to the increasing of strike price. Conversely, there is an increasing for put option value with respect to the increasing of strike price. The put options with continuous dividends has higher value than put option value with discrete dividends. Then the call options results with discrete dividends are higher than the results with continuous dividends.

Figure 5 shows the comparison results of $S=1000, N=12$, and the given $K$. On the previous simulation, the small value of $S$ did not affect call option price movement. But this simulation shows that a large value of $S$ induces the decreasing of call options value with respect to the increasing of initial stock value. The put options is increasing with respect to the increasing of the initial stock price. The effect of the dividends gives a higher value of call options with discrete dividends than continuous dividends. Conversely, put options with continuous dividends has a higher value than put options 
TABLE VII: Comparison With $S=50, N=1100$ and Different Strike Price Value

\begin{tabular}{c||cc||cc}
\hline \multicolumn{1}{c||}{ K } & \multicolumn{2}{c||}{ Call Option } & \multicolumn{2}{c}{ Put Option } \\
& Discrete & Continuous & Discrete & Continuous \\
\hline \hline 34 & 16.6780 & 16.0049 & 1.3079 & 1.7799 \\
80 & 1.5225 & 1.0505 & 38.0574 & 38.0574 \\
105 & 0.3787 & 0.2352 & 63.0574 & 63.0574 \\
200 & 0.0030 & 0.0014 & 158.0574 & 158.0574 \\
350 & $6.8346 \times 10^{-6}$ & $2.4908 \times 10^{-6}$ & 308.0574 & 308.0574 \\
500 & $5.2813 \times 10^{-8}$ & $1.6269 \times 10^{-8}$ & 458.0574 & 458.0574 \\
900 & $3.1997 \times 10^{-12}$ & $4.2264 \times 10^{-13}$ & 858.0574 & 858.0574 \\
1100 & $7.0547 \times 10^{-14}$ & $1.4906 \times 10^{-14}$ & $1.0581 \times 10^{3}$ & $1.0581 \times 10^{3}$ \\
1800 & $1.9254 \times 10^{-18}$ & $3.1996 \times 10^{-19}$ & $1.7581 \times 10^{3}$ & $1.7581 \times 10^{3}$ \\
2500 & $7.5145 \times 10^{-22}$ & $1.0654 \times 10^{-22}$ & $2.4581 \times 10^{3}$ & $2.4581 \times 10^{3}$ \\
3000 & $6.8118 \times 10^{-24}$ & $8.8283 \times 10^{-25}$ & $2.9581 \times 10^{3}$ & $2.9581 \times 10^{3}$ \\
\hline
\end{tabular}

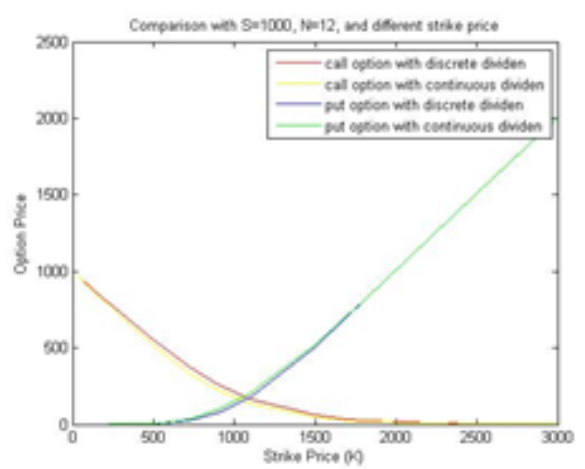

Fig. 5: Comparison graphics with $S=1000, N=12$, and different strike price.

with discrete dividends.

The following simulations are performed by using initial stock parameter and great number of step value which is $S=$ 1000 and $N=1100$. Same as before, the result on Fig. 6 shows that a large value of $S$ induces the decreasing of call options value with respect to the increasing of initial stock value. The put options are increased with respect to the increasing of the initial stock price. The great $N$ gives more accurate result for every result of options value. The effect of the dividends gives a higher value of call options with discrete dividends than continuous dividends. Conversely, put options with continuous dividends has a higher value than put options with discrete dividends.

\section{CONCLUSIONS}

This research shows that the exist of dividends give some impact to the option pricing. The existing of dividend given as follow:

1) The greater $N$ values, the more accurate result of option value. The given $N$ affects option price will convergent to a certain value.

2) The effect of dividends on option value gives the call options values with discrete dividends are always higher than the call options with continuous dividend. While the put options with continuous dividend always has

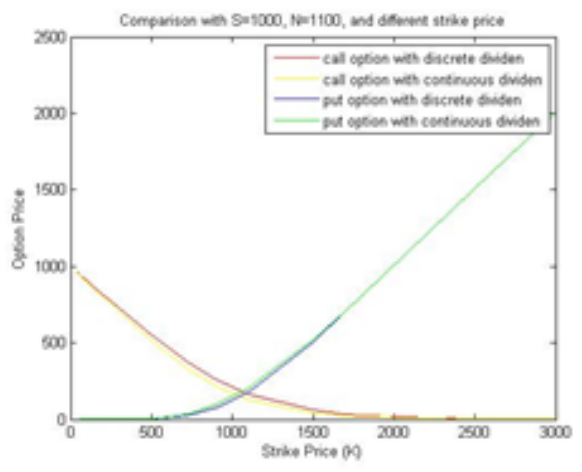

Fig. 6: Comparison graphics with $S=1000, N=1100$, and different strike price.

a higher value than the put options with a discrete dividend.

\section{REFERENCES}

[1] J. Cox, S. Ross, and M. Rubinstein, "Option pricing: A simplified approach," Journal of financial Economics, vol. 7, no. 3, pp. 229-263, 1979.

[2] M. Gilli and E. Schumann, "Implementing binomial trees," Available at SSRN 1341181, 2009.

[3] G. Barone-Adesia, N. Fusarib, and J. Thealc, "Binomial lattices for barrier options," Quantitative and Qualitative Analysis in Social Sciences, vol. 2, no. 2, pp. 63-70, 2008.

[4] B. Peng and F. Peng, "Pricing jump diffusion american call option with dividends," in 2nd IEEE International Conference on Information and Financial Engineering, 2010, pp. 827-831.

[5] G. Jiang, S. Wang, and H. Dong, "Valuation and optimal exercise time of american call option on stock paying stochastic dividends," in 3rd International Workshop on Intelligent Systems and Applications, 2011, pp. $1-4$. 